\title{
Numerical Simulation of the Seepage Field and the Analysis of its Sensibility Based on Finite Element Method
}

\author{
Hongyang Zhang ${ }^{*}$ Xianqi Zhang* and Cundong Xu
}

\author{
School of Water Conservancy, North China University of Water Resources and Electric Power, Zhengzhou, China
}

\begin{abstract}
The distribution characteristics and migration mechanism of seepage field of reservoir groundwater can determine the geographical characteristics of reservoir area to a large extent. The permeability of reservoir area is especially important since it is an important indicator of karst development characteristics and its hydrogeological condition in karst area, and it's difficult to conduct quantitative analysis of its parameters. According to the needs of practical engineering application, I use the C\# and FORTRAN program to design a calculation method. I also use seepage field numerical simulation in reservoir area of one pumped storage power station on the east to testify the correctness and practicability of this calculation method. Judging from the groundwater level contour map, we can see that groundwater shed and surface water shed are basically the same. Groundwater can be distributed to surrounding areas from the upper reservoir. Because of the resistance effect of non-karst area on north and south, groundwater flows out in the form of spring in north and south. The groundwater flows to Zimei Bridge on east side, and Yaoshiwan on west side. The repeated experiments of parameters show that groundwater seepage field is insensitive to the change of other areas' permeability parameter. Results show that this calculation method is well-adapted, accurate, applicable and practical.
\end{abstract}

Keywords: Finite element method, hydrogeology, seepage field, sensitivity analysis, numerical simulation.

\section{INTRODUCTION}

Studies of seepage of reservoir groundwater are mostly based on linear Darcy's law, because under normal circumstances, groundwater seepage can satisfy or nearly satisfy Darcy's law, and the linear relation of Darcy's law also makes the analysis of theories and data more concise. However, reservoirs built in karst areas may have strongly permeable geologic structure. So the seepage has high Reynolds number, and the seepage speed and hydraulic slope do not conform to the Darcy's law, thus we have to take inertial force into consideration. Chai Junrui [1] and Dai Qunli [2] deem it necessary to do nonlinear analysis of groundwater seepage of dam foundations in karst areas. Because of the complexity of nonlinear seepage, there is no unified formula to describe this seepage. Two frequently used empirical formulas are Forchheimer formula [3-5] and nonlinear seepage formula. The latter is got by applying the first one in a continuity equation of three-dimension. Most frequently used ways to analyze the data of seepage include: finite difference method, finite element method, boundary element method and etc. All these methods are built on the theory of continuous medium seepage. Finite element method is a commonly used numerical method.

It combines classical variation method and polynomial interpolation, its essence is the discretization of area. In 1965, ienkiewiz and Cheung brought up finite element

*Address correspondence to this author at the School of Water Conservancy, North China University of Water Resources and Electric Power, Zhengzhou, China; Tel/Fax: +86-0371-69127403;

E-mail: zhangxianqi@ncwu.edu.cn method to address all field problems that can be calculated in variation from, thus providing theoretical basis for its application in the analysis of seepage. Leiws R W [6] used this method to simulate groundwater in porous medium. Many domestic researches (G. Eason, B. Noble, and I. N. [7]; Zienkiewich O. C and Taylor R. L [8]; Felippa C A et al., [9]; Kanghong Li and Junrua Chai [10]; ShuWang Yan et al. [11]; Takafumi Sugiyama et al. [12]; Shaoyun Song [13]) believe that finite element method is an advanced and effective numerical simulation method. When analyzing seepage, it can partially replace model test, it has relatively high accuracy and can simulate many external conditions. This essay uses the FORTRAN program written by myself. I also write the finite element computer program targeting towards this condition, and conduct parameter inversion analysis. The results are ideal.

\section{CASE STUDY}

\subsection{General Situation of Geological Environment}

One pumped storage power station on the east has an installed capacity of 1350MW. The power station composes of upper storage reservoir, lower storage reservoir, water conveyance system, underground powerhouse and other constructions. The concrete faced rockfill dam of upper storage reservoir measures $183.5 \mathrm{~m}$ to the highest, and the total storage is $17,030,000 \mathrm{~m}^{3}$; the concrete faced rockfill dam of lower storage reservoir measures $33.4 \mathrm{~m}$ to the highest, and the total storage is $16,760,000 \mathrm{~m}^{3}$. The reservoir is next to Yangtze River to the north and Tai Lake to the south. It is situated in the hilly areas of Ningzhen Mountains. It's high in the west and low in the east. Its terrain is not 


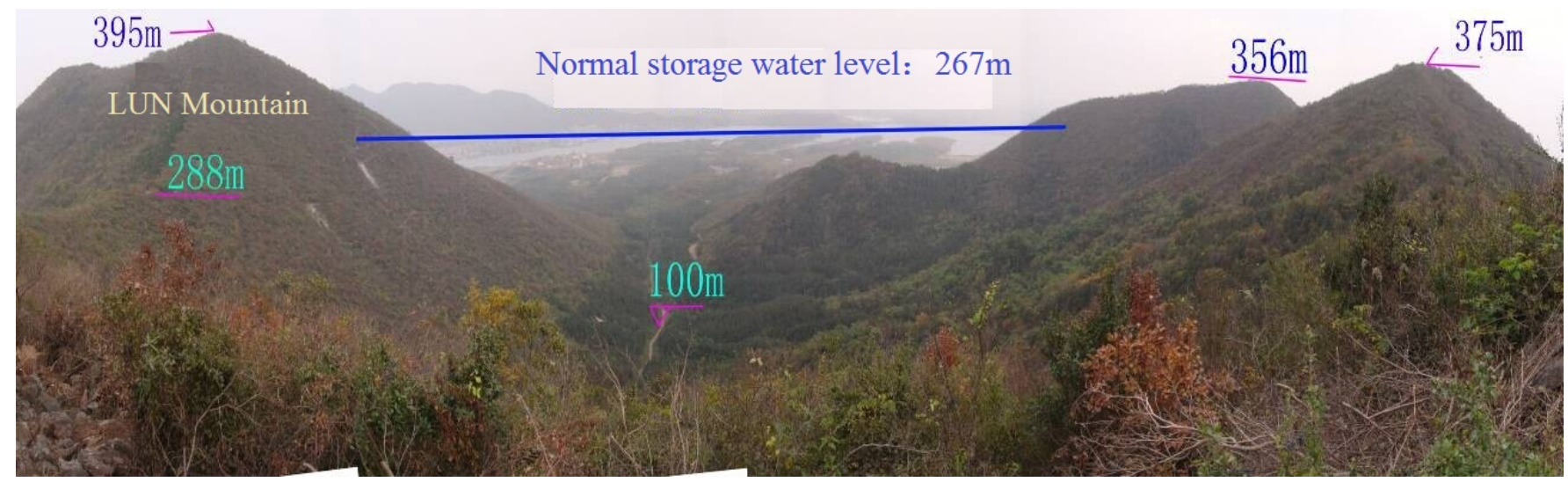

Fig. (1). Landform of upper storage reservoir.

deep, and it has ravines, denudation landform, multi-stage planation surface, 3-4 level terrace, corresponding stratified karst and deeply incised valleys (Fig. 1).

The stratum of the reservoir area is very complicated, the mains strata are dololithite of $\mathrm{Z}_{2} \mathrm{dn}$, phosphoric dolomite of $\epsilon_{1} \mathrm{~m}^{2}$, argillaceous dolomite of $\epsilon_{1}$ p, siliceous dolomite of $\epsilon_{2-3}$ gn, lime dolostone of $\mathrm{O}_{1} \mathrm{l}$, micrite of $\mathrm{P}_{1} \mathrm{q}$, calcareous and argillaceous siltstone of $\mathrm{P}_{2} \mathrm{l}$, brecciaous limestone of $\mathrm{T}_{1} \mathrm{x}$, brecciaous limestone of $T_{2} z$, siltstone of $K_{1} y$ and etc. The strata of this area consists of geofracture, such as eastern sector of Long Mountain- Bei Mountain fault $\left(\mathrm{F}_{10}, \mathrm{~F}_{11}\right)$, the “ 入” shaped structural belt of Jintiao Mountain $\left(\mathrm{F}_{1} \sim \mathrm{F}_{4}\right)$, Zimei Bridge- Iigang fracture $\left(\mathrm{F}_{12}\right)$, eastern sector of Fairy Cave fault $\left(\mathrm{F}_{9}\right)$. NW-trending faults are common and NE-trending faults are relatively rare. Karst rock near the reservoir area mainly consists of strata made of dolomite, such as sinian system (Z), cambrian system $(\epsilon)$, and strata made of imestone, such as ordovician system $(\mathrm{O})$, permian system $(\mathrm{P})$, triassic system $(\mathrm{T})$, and carboniferous system $(\mathrm{C})$. The reservoir area can be divided into four karst hydrogeology types according to the development degree of karst, formation lithology, geological structure, storage and transport of karst wate. The first type is non-karst area. In the A area - under or medium-developed hydrogeology area of bare type pure carbonate monoclinic karst, most of the bedrocks are exposed to the air, and lithology changes from dolomite to limestone. The seepage field area under analysis in this essay is the pivotal project of the water power generation system at the upper storage reservoir. It's west boundary is F7, north boundary F4, east boundary F12-1 at the east slope toe of Lun Mountain and the concomitant diorite porphyrite veins and P2l, south boundary $\mathrm{O} 3$ at the south slope toe of Lun Mountain. The B area-mediumdeveloped hydrogeology area of the inter-bedded or interlayer karst of bare type pure carbonate and non-karst is located at the slope toe of Lun Mountain, the west edge of lower storage reservoir. The $\mathrm{C}$ area-under or mediumdeveloped hydrogeology area of bare type pure anticline karst is at the west of upper storage reservoir. Non-karst area is composed of siltstone, trachyte, diorite porphyrite and etc, and is mainly distributed at the north of lower storage reservoir and Lun Mountain reservoir at the south slope toe of Lun Mountain.

\section{NUMERICAL SIMULATION AND RESULT ANALYSIS OF SEEPAGE FIRLD}

\subsection{Mathematical Modeling}

Because groundwater does not change much during dry seasons, so we can regard the groundwater movement as steady flow. So the groundwater movement in this studies area is a two-dimensional flow in isotropic and heterogeneous mediums. Its mathematical model is like this:

$$
\begin{aligned}
& \int \frac{\partial}{\partial x}\left(K(x, y) \frac{\partial H}{\partial x}\right)+\frac{\partial}{\partial y}\left(K(x, y) \frac{\partial H}{\partial y}\right)+W=0 \text { 在为 } \\
& \left\{H=H_{b}(x, y)\right. \\
& T_{x} \frac{\partial H}{\partial x} \cos (n, x)+T_{y} \frac{\partial H}{\partial y} \cos (n, y)=q \\
& \text { 在声 } \\
& \text { 在声 }
\end{aligned}
$$

In this model, $\Omega$ is the computational area; $\Gamma_{1}$ is the first kind of boundary; $\Gamma_{2}$ is the second kind of boundary; $H$ is the known water heads at the first kind of boundary; $n$ is the direction of exterior normal at the first kind of boundary; $q$ is the unit discharge at the normal of second kind of boundary (in is plus, out is minus); $W$ is the water resource infiltrated by rainfall. The simplified finite element equation is:

$$
[G]\{H\}=\{W\}+\{F\}
$$

Thus we can get the NN-order linear equation, and we can get the water heads at these NN nodes by solving the equation.

\subsection{Geometric Modeling and Parameter Choosing}

The study area can be divided into 5 sub-areas (Fig. 2) according to formation lithology, karst hydrogeology unit, and landform. The north boundary is at $F_{3}$, south boundary at $\mathrm{F}_{9}$, east boundary at the drill 25 near $\mathrm{F}_{12}$ of Zimei Bridge and the west boundary at $\mathrm{F}_{7}$.

Area I: sandstone and siltstone of silurian system fentou formation between $F_{4}$ and $F_{3}$; area II: from $F_{7}$ to $F_{8}$, and 
stretches to $F_{4}$ to the north, ridge of Lun Mountain to the south; area III: triangular area formed by $\mathrm{F}_{12}, \mathrm{~F}_{8}$ and the ridge of Lun Mountain; area IV: between $\mathrm{F}_{7}$ and $\mathrm{F}_{8}$, at the south of the ridge of Lun Mountain; area $\mathrm{V}$ : the east of $\mathrm{F}_{8}$, the south of the ridge of Lun Mountain. The study area is divided into 2056 triangular units and 1092 nodes as shown in Fig. (3).

To sufficiently use observational data, I set the drill groundwater level of the upper reservoir as the first boundary condition of the upper reservoir and flow point of spring at the lower reservoir as the boundary condition.

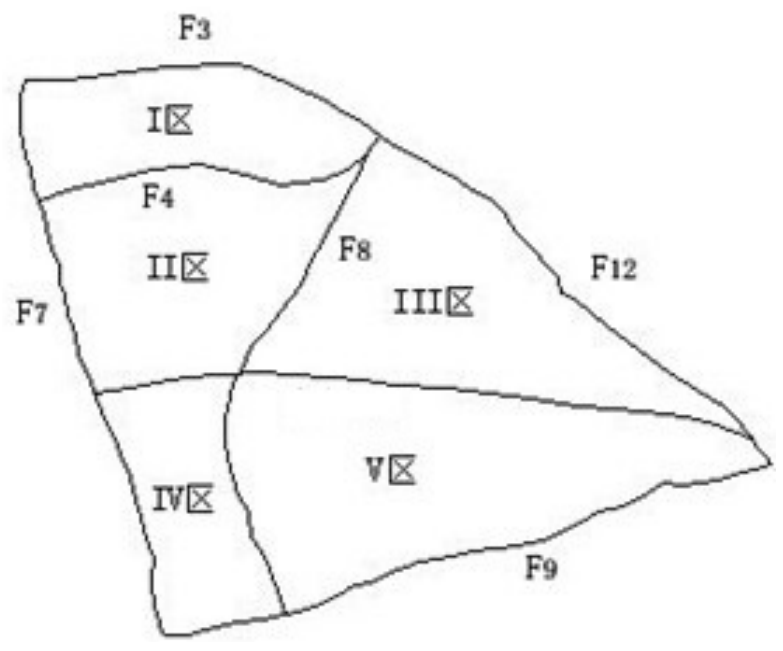

Fig. (2). Reservoir partition.

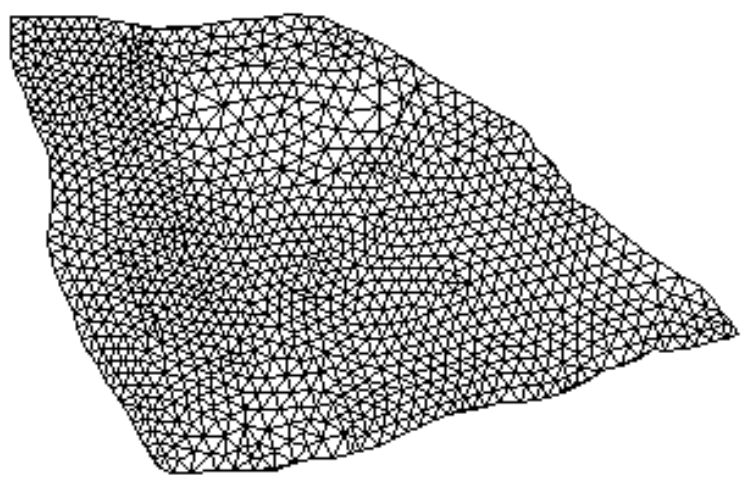

Fig. (3). Finite element graph of reservoir area.

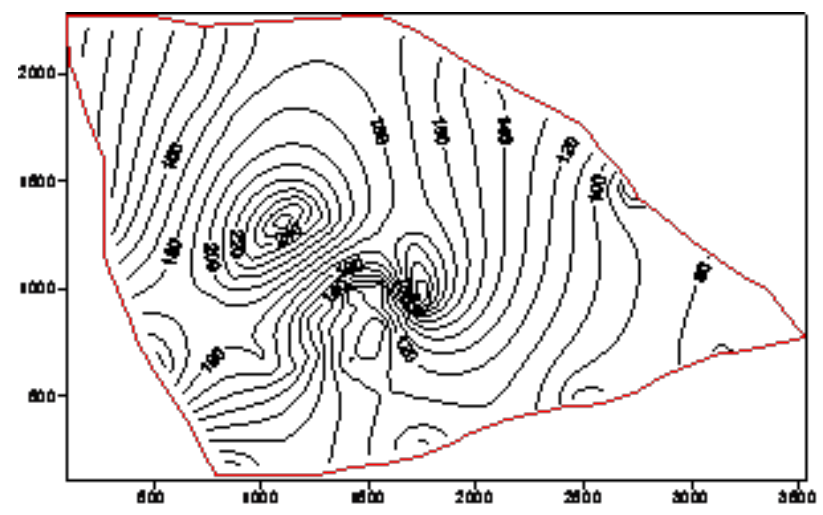

(a) Plane graph

Fig. (4). Groundwater level contour map in reservoir area.
The parameters are due to combining the calculated value and tested value of water pressure test. According to the water pressure test, the osmotic coefficients value of infiltration area I is $0.0175 \mathrm{~m} / \mathrm{d}$; infiltration area II $0.00864 \mathrm{~m} / \mathrm{d}$; infiltration area III $0.0195 \mathrm{~m} / \mathrm{d}$; infiltration area IV $0.021 \mathrm{~m} / \mathrm{d}$; infiltration area V $0.0187 \mathrm{~m} / \mathrm{d}$. We should also take the infiltration recharge by rainfall into consideration. According to record of rainfall in Lun Mountain reservoir, the average rainfall in January is $46.1 \mathrm{~mm}$, i.e., $1.54 \mathrm{~mm} / \mathrm{d}$. As most of rainfall soaks into the ground, so the rainfall infiltration coefficient is 0.55 .

\subsection{Numerical Simulation Result and Analysis}

Based on the mathematical model above, I use twodimensional finite element program written by FORTRAN to do simulated calculation of reservoir water level contour map of seepage field as shown in Fig. (4).

The northwest, west, southwest watershed of the upper reservoir are all in this sub-region. Judging from the groundwater level contour map, we can see that, groundwater shed and surface water shed are basically the same. Groundwater can be distributed to surrounding areas from the upper reservoir. Because of the resistance effect of non-karst area (aquitard) on north and south, so groundwater flows out in the form of spring in north and south. There is a watershed at the ridge of Lun Mountain, so groundwater flows to the south and north of the ridge while flowing east. At the south of upper reservoir, groundwater flows to the gully to the north of Dashao Spring. The groundwater goes to Zimei Bridge on east side. On the north, there is one north-south trending watershed, so groundwater flows to the east and west side while flowing towards north. On the west side, groundwater flows to Yaoshiwan on west side, the same flow direction as surface water.

To guarantee the accuracy of calculation, I set 2 groundwater level observatory points at every sub-areas, altogether 10 groundwater level observatory points, to compare the calculated value with the measured value. The calculated value and measured value are shown in Table $\mathbf{1}$ and Fig. (5).

We can see from Table 1 and Fig. (5) that measured value and calculated value are very close, the maximum

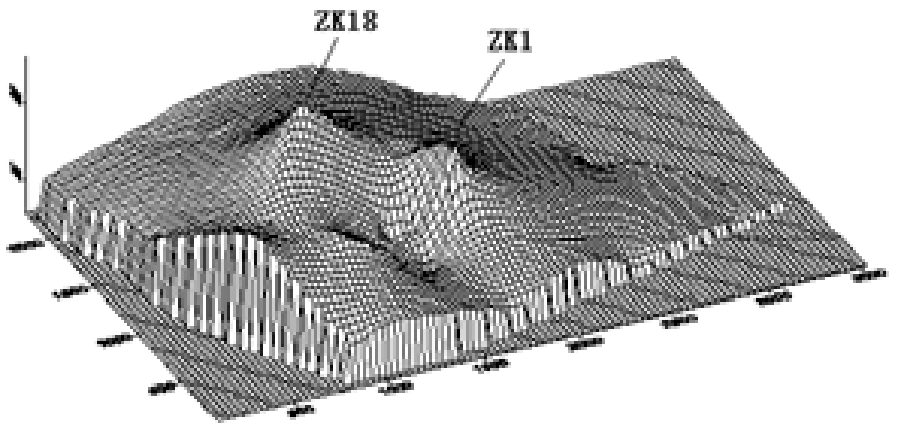

(b) Stereogram 
errors, at $\mathrm{I}_{2}$ and $\mathrm{III}_{1}$, are less than $5 \mathrm{~m}$; the minimum error, at $\mathrm{V} 2$, is $2 \mathrm{~m}$, the maximum relative error is $2.6 \%$. So the model is accurate, and this method is correct and practical.

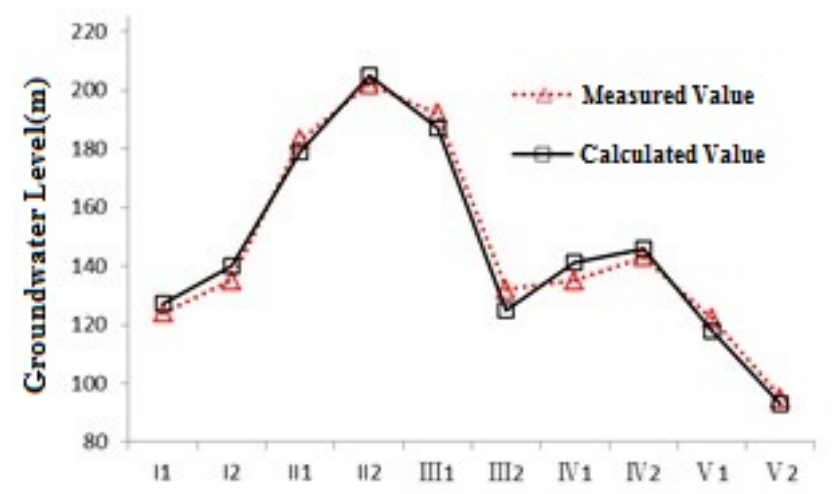

Fig. (5). Measured value and calculated value.

\section{SENSITIVITY ANALYSIS OF MODELING PARAMETERS}

Because the geological and hydrogeological study of this area in an on-going process, so many parameters are undetermined, so I can do sensitivity analysis of parameters to analyze the movement of groundwater under different parameters, and analyze the sensibility of parameters to seepage field.
In permeability partition IV, karst is highly developed, and its coefficient of permeability is doubled with other parameters unchanged. The results are shown in Fig. (6).

Table 1. Measured value and calculated value.

\begin{tabular}{|c|c|c|c|c|c|}
\hline No. & I1 & I2 & II1 & II2 & III \\
\hline \hline Measured value & 124 & 135 & 183 & 202 & 192 \\
\hline Calculated value & 127 & 140 & 179 & 205 & 187 \\
\hline No. & III2 & IV1 & IV2 & V 1 & V 2 \\
\hline Measured value & 132 & 135 & 143 & 122 & 95 \\
\hline Calculated value & 128 & 139 & 146 & 118 & 93 \\
\hline
\end{tabular}

In permeability partition I, karst is under developed, and its coefficient of permeability is reduced by $1 / 2$ with other parameters unchanged. The results are shown in Fig. (7).

In permeability partition III, karst is relatively under developed. To make the results reliable, its coefficient of permeability is the same as that of permeability partition IV with other parameters unchanged. The results are shown in Fig. (8).

We can see from Fig. (6) to Fig. (8) that the change of permeability partition IV and permeability parameter can

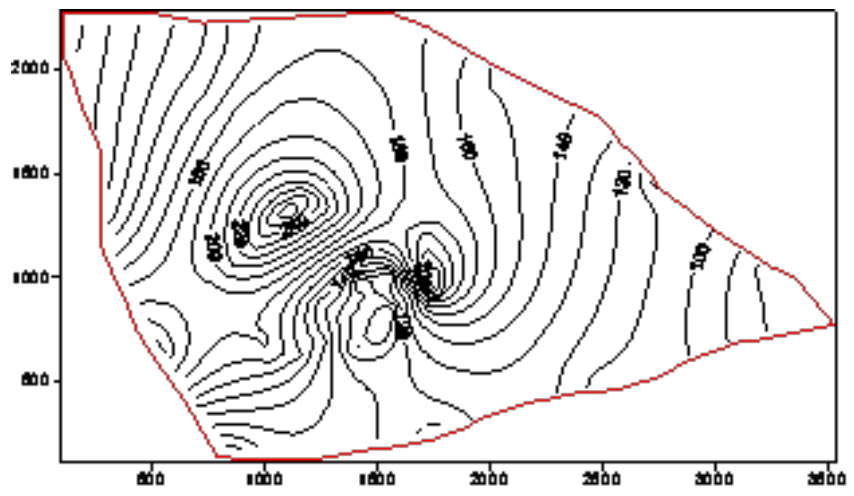

(a) Plane graph

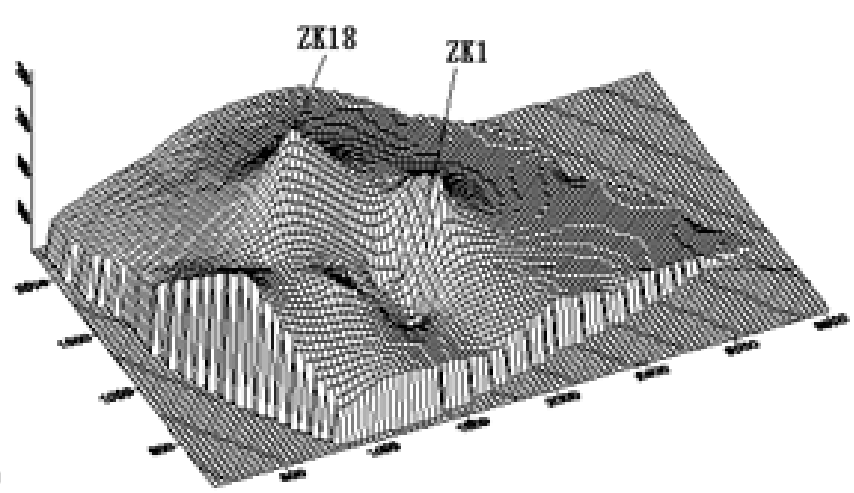

(b) Stereogram

Fig. (6). Groundwater level contour map of the study area when the parameters of permeability partition IV change.

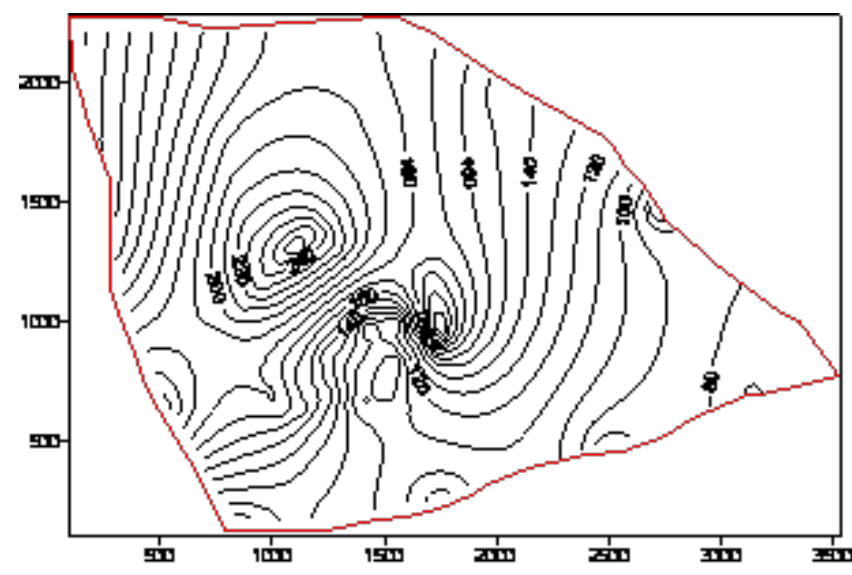

(a) Plane graph

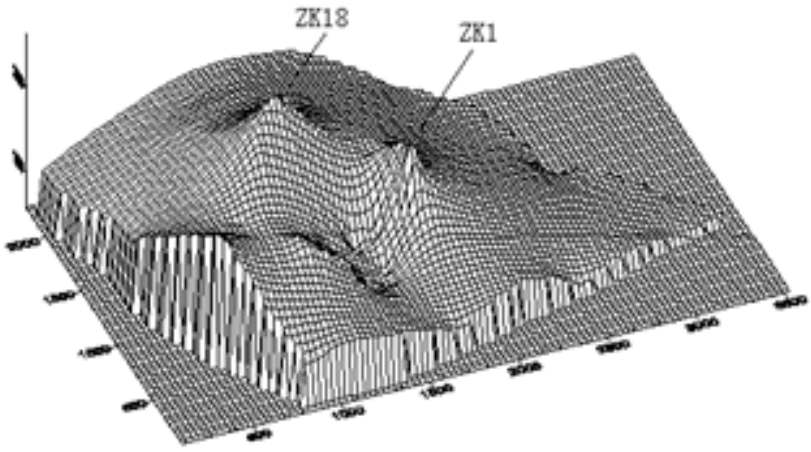

(b) Stereogram

Fig. (7). Groundwater level contour map of the study area when the parameters of permeability partition I change. 


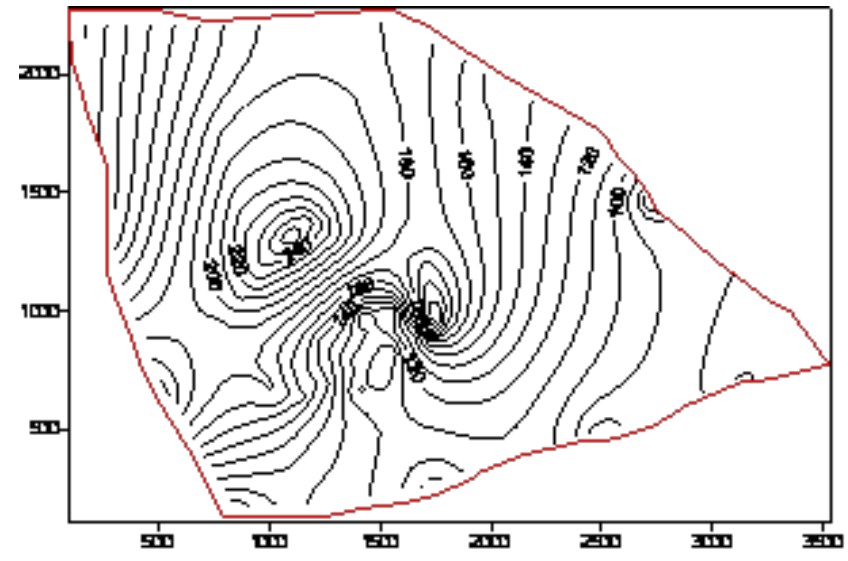

(a) Plane graph

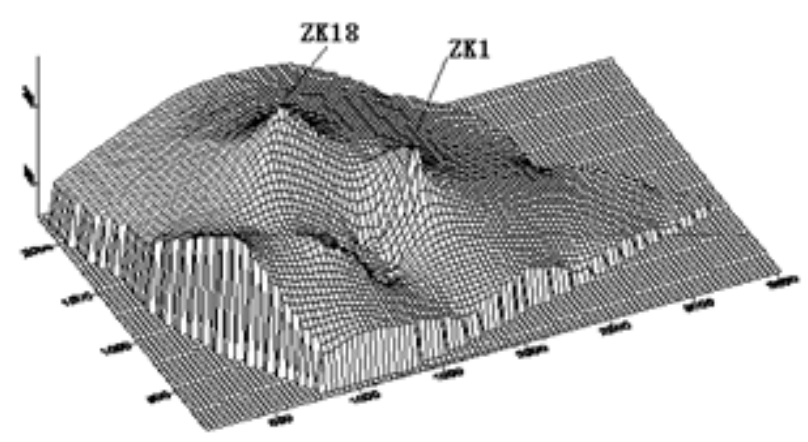

(b) Stereogram

Fig. (8). Groundwater level contour map of the study area when the parameters of permeability partition III change.

influence the groundwater seepage field greatly, but the general trend is the same as Fig. (4). When the permeability parameter of other partitions change, groundwater seepage field does not change greatly, so the groundwater seepage field is insensitive to the change of permeability parameters of other partitions.

The analysis of seepage field of study area shows that between the east of ZK1 drill and north slope and south slope of Lun Mountain, there exists a watershed. So groundwater flows to the east while flowing on the south and north side of the watershed. Because of the resistance effect of non-karst area on north and south slope of Lun Mountain, so groundwater flows out in the form of spring in north and south. In this calculation process, I do not separate this highpermeability region individually, so the result does not show the condition of low water tank. The seepage calculation result only shows the general trend of groundwater movement in the study area.

The change of permeability of areas to the east of $\mathrm{F}_{8}$ can influence the groundwater seepage field a lot, while the change of permeability in other areas will not.

\section{CONCLUSION}

According to the needs of practical engineering application, I use FORTRAN program to write computer program to simulate the seepage field of the reservoir. It is proved that this method is correct and practical.

We can see from the groundwater level contour map that groundwater shed is the same as surface water shed. Groundwater can be distributed to surrounding areas from the upper reservoir. Because of the resistance effect of nonkarst area on north and south, so groundwater flows out in the form of spring in north and south. The groundwater flows to Zimei Bridge on east side, and Yaoshiwan on Ist side.

The repeated simulation of parameters show that the change of permeability partition IV and permeability parameter can influence the groundwater seepage field a lot, while the change of permeability parameter of other partitions cannot.

\section{CONFLICT OF INTEREST}

The authors confirm that this article content has no conflict of interest.

\section{ACKNOWLEDGEMENTS}

The authors wish to thank the National Natural Science Foundation of China for contract 51279064 and 31360204, NSFC-Henan Provincial People's Government Joint Fund of Personnel Training (No.U1304511), and Open Fund of China Institute of Water Resources and Hydropower Research of China for contract IWHR-SKL-201110, under which the present work was possible.

\section{REFERENCES}

[1] C. Junrui, "Analysis of non-darcy seepage through dam foundation," Water Resources and Power, vol. 19, no. 4, pp. 1-3, April 2001.

[2] Q. Dai, "The simulation of the non-linear flow of groundwater," Hydrogeology and Engineering, Geology, vol. 27, no. 2, pp. 50-51, February 2000.

[3] J. Bear, Hydraulics of Ground Water. Mcgraw-hill Press, New York, 1979, pp. 175-83.

[4] C. Willis, and J. Rubin, "Transport of reactive solutes subject to a moving dissolution boundary: numerical methods and solution," Water Resource Research, vol. 23, no. 8, pp. 1561-1574, August 1987.

[5] Y. M. Lee, and K. J. Lee, "Nuclide transport of decay chain in the fractured rock medium: a model using continuous time Markov process," Annals of Nuclear Energy, vol. 22, no. 2, pp. 71-84, February 1995.

[6] R. W. Leiws, and B. A. Schrefler, The Finite Element Method in The Deformation and Consolidation of Porous Media. John Wiley Press, New York 1987, pp. 86-98.

[7] G. Eason, B. Noble, and I. N. Sneddon, "On certain integrals of Lipschitz-Hankel type involving products of Bessel functions," Philosophical Transactions of the Royal Society of London, vol. A247, pp. 529-551, April 1955.

[8] O. C. Zienkiewich, and R. L. Taylor, The Finite Element Method. Butterworth Heinemann Press, London: 2000; pp. 115-37.

[9] C. A. Felippa, K. C. Park, and C. Farhat, C, "Partitioned analysis of coupled mechanical systems," Computer Methods in Applied Mechanics and Engineering, vol. 190, pp. 3247-3270, March 2001.

[10] L. Kanghong, and C. Junrua, "Comparison of two numerical methods for seepage analysis through dam foundation," Hongshui River, vol. 22, no. 4, pp. 14-17, April 2003.

[11] Y. S. Wang, W. R. Gang, W. X. Jun, and L. S. Ming, "Finite element analysis of seepage fields at Baishi earth dam," Journal of 
Hydroelectric Engineering, vol. 22, no. 2, pp. 53-61, February 2003.

[12] S. Takafumi, R. Worapatt, and T. Yukikazu, "Simultaneous transport of choride and calcium lons in hydrated cement systems," Journal of Advanced Concrete Technology, vol. 1, no. 2, pp. 127138, February 2003.
[13] S. Shaoyun, "Modeling of multiphysics problem and research of coupling relation," Journal of Wuhan Polytechnic University, vol. 27, no. 3, pp. 46-49, March 2008.

(c) Zhang et al.; Licensee Bentham Open.

This is an open access article licensed under the terms of the Creative Commons Attribution Non-Commercial License (http://creativecommons.org/licenses/ by-nc/3.0/) which permits unrestricted, non-commercial use, distribution and reproduction in any medium, provided the work is properly cited. 